Sharif University of Technology
Scientia Iranica
SCIENTIA
IRAN I CA

\title{
A new technique of the "first and second limits" for wagon maintenance in railway tracks consisting of sharp curves based on the empirical study of wheel wear
}

\author{
S.M. Salehi, G.H. Farrahi* and S. Sohrabpour \\ School of Mechanical Engineering, Sharif University of Technology, Tehran, Iran.
}

Received 6 March 2016; accepted 2 July 2016

KEYWORDS
Wheel wear;
Maintenance
technique;
Sharp curves;
Empirical study;
Wheel longevity
enhancement;
Wheel flange wear
behavior;
Wagon's maintenance
cost enhancement.

\section{KEYWORDS}

\begin{abstract}
Wheel wear is one of the major costs in railway tracks consisting of sharp curves. In this paper, wear behavior of S1002 profiles of wheels in the "Southern Line" of Iran's railway, which consists of a large number of distinct and/or consecutive sharp curves, is studied using the field data measuring technique. Based on wear behavior analysis of all wheels, an optimal wagon maintenance technique called the "first and second limits" is suggested to minimize the wagon's cost per traveled distance. The results show that: 1) A severe wheel flange wear occurs for all wheels in comparison to the wheel tread wear in normal tracks; 2) A wagon's detachment for repair of critical wheels on its four axles occurs at the traveled distances of $40,000 \mathrm{~km}, 54000 \mathrm{~km}, 71000 \mathrm{~km}$, and $75000 \mathrm{~km}$, respectively (much less than the normal traveled distance of $500,000 \mathrm{~km}$ ); 3 ) A fifth order polynomial function can be appropriated to represent the wear behavior of the wheels; 4) By implementing the suggested technique, the cost per traveled distance decreases by $38.64 \%$, and the travelled distance increases by $45 \%$.

(C) 2017 Sharif University of Technology. All rights reserved.
\end{abstract}

\section{Introduction}

Railway is one of the most efficient transportation systems in terms of economy, energy consumption, and safety factors [1]. Wear of wheel and rail is an inevitable issue which reduces the safety, comfort, and consequently the efficiency of the transportation while increasing the costs [2-4]. Although, the conical geometry of the wheel, especially the wheel flange at its inner edge prevents the derailment of the wagon, as shown in Figure 1(a), the wear phenomenon may cause the derailment of the wagon in the worst case scenario.

The importance and costs of wear in railways as well as its influence on the maintenance of the wheel

*. Corresponding author. Tel.: +982166165533;

Fax: +982166000021

E-mail addresses: s_m_salehi@mehr.sharif.ir (S.M. Salehi); farrahi@sharif.edu (G.H. Farrahi); saeed@sharif.ir (S. Sohrabpour) and wagon have been a matter of concern for experts in this industry [5-8]. Thus, study on the evolution of the wheel profile due to wear phenomenon could be employed to optimize wheel and rail profiles, in addition to enhancing the maintenance conditions. In ordinary railways, wear occurs in all regions of the wheel surface in contact with the rail (shown schematically in Figure 1(b)). However, the contact of wheel and rail in curves and the train's unilateral tendency to the inner rail considerably increase the wheel and rail wear, and in particular cause an asymmetrical wheel flange wear $[9,10]$. The size and shape of the contact area between two elastic bodies with a static mode of contact were recognized by Hertz [11]. Hertz's theory expresses that the elastic deformation of steel wheels and rails creates an elliptical contact surface [11]. Many researchers, such as Kalker [12], attempted to develop Hertz's theory resulting in several analytical and numerical models being developed for the contact 


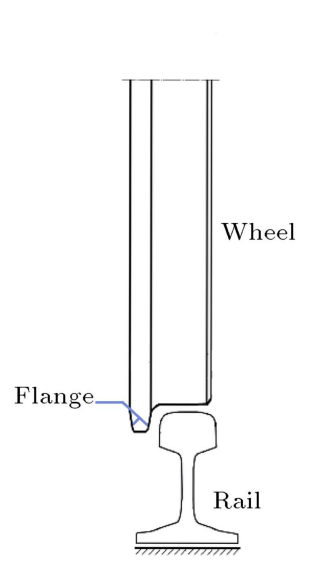

(a)

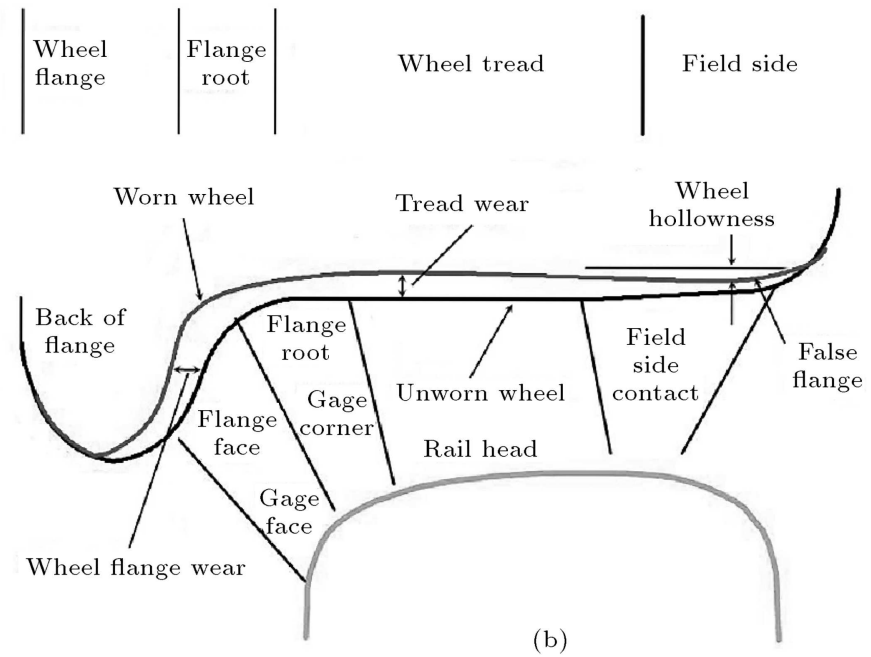

(b)

Figure 1. The schematic of (a) a contact of wheel and rail, and (b) the worn regions of the wheel profile in contact with rail.

and wear problems [3,13]. Li [14] developed multifocal non-Hertzian and conformal contact models. Many studies have been dedicated to finding a significant relationship between the contact status and wear rate while considering plasticity models and modelling the contact stress [15-17]. These models have focused on the evolution of wheel and rail profiles when moving straight or in low curved tracks such as Zobory [18], Jendel and Berg [19], Blokhin et al. [20], and Ushkalov et al. [21]. Due to the complexities of the problem, the effects of sharp curves on some particular railways have not been included in such models.

Several important research activities have been also conducted using the experimental approach to the problem of wheel-rail wear since the mid-eighteenth century $[4,22,23]$. The experimental studies on wheel and rail wear are performed through two techniques: laboratory modeling and real-scale field data recording. By using the real-scale field data recording technique, we can infer important findings that cannot be achieved by laboratory modeling technique. In this technique, there is no need for any kind of correction factors to apply to the experimental results.

Over $90 \%$ of major failures of the railway systems are due to wheel wear, according to the report of Iran's Railway Transportation System (IRTS) [5]. Particularly, over $70 \%$ of these failures occur due to the sharp shrinkage or severe wear of wheel flange in the "Southern Line" of Iran's railway system (2.32 to 4.55 times more than other lines, according to Table 1 ). According to surveys, this phenomenon originates from the large number of sharp curves in this track (i.e., curves with a radius of less than $300 \mathrm{~m}$ in which trains travel with a maximum speed of about $120 \mathrm{~km} / \mathrm{h}$ through them). This problem increases the wagon detachment considerably and reduces the longevity of wheels from more than the usual amount of $500,000 \mathrm{~km}$
Table 1. The rates of wheel wear in Iran's rail lines relative to the "Hormozgan Line" in 2015. The highlighted railway called the "Southern Line" has the greatest wear rate [5].

\begin{tabular}{lc}
\hline Railway name & $\begin{array}{c}\text { Relative wearing rate } \\
\text { with respect to the } \\
\text { Hormozgan railway }\end{array}$ \\
\hline Hormozgan & 1 \\
Southern & $\mathbf{4 . 5 5}$ \\
Azerbaijan & 1.96 \\
Northern & 1.18 \\
Khorasan & 1.09 \\
\hline
\end{tabular}

to less than $50,000 \mathrm{~km}$. This problem is one of the most significant issues in the rail industry of Iran.

In this paper, the wear behavior of wagon's wheels is studied using the field data recording technique in real operational state, in particular Southern Line of Iran's railway which consists of many distinct and consecutive sharp curves (created due to the geological limits). Based on the wear behavior study of wheels, an optimal wagon maintenance technique is suggested and discussed. This technique is based on the minimum cost per traveled distance, the wheels repairing costs, and the wagon detachment costs. The technique discusses the worn wheel flange thickness limit of standard UIC510-2 [24] which forces the detachment of wagon for repairing the worn wheel and suggests two limits. The procedure implemented in this work to study on the wear behavior as well as the proposed technique for the maintenance of wagon wheels with the satisfaction of the standard limits, could be employed in similar railways consisting of sharp curves found in mountainous countries such as Iran, Italy, Australia, India, etc. 


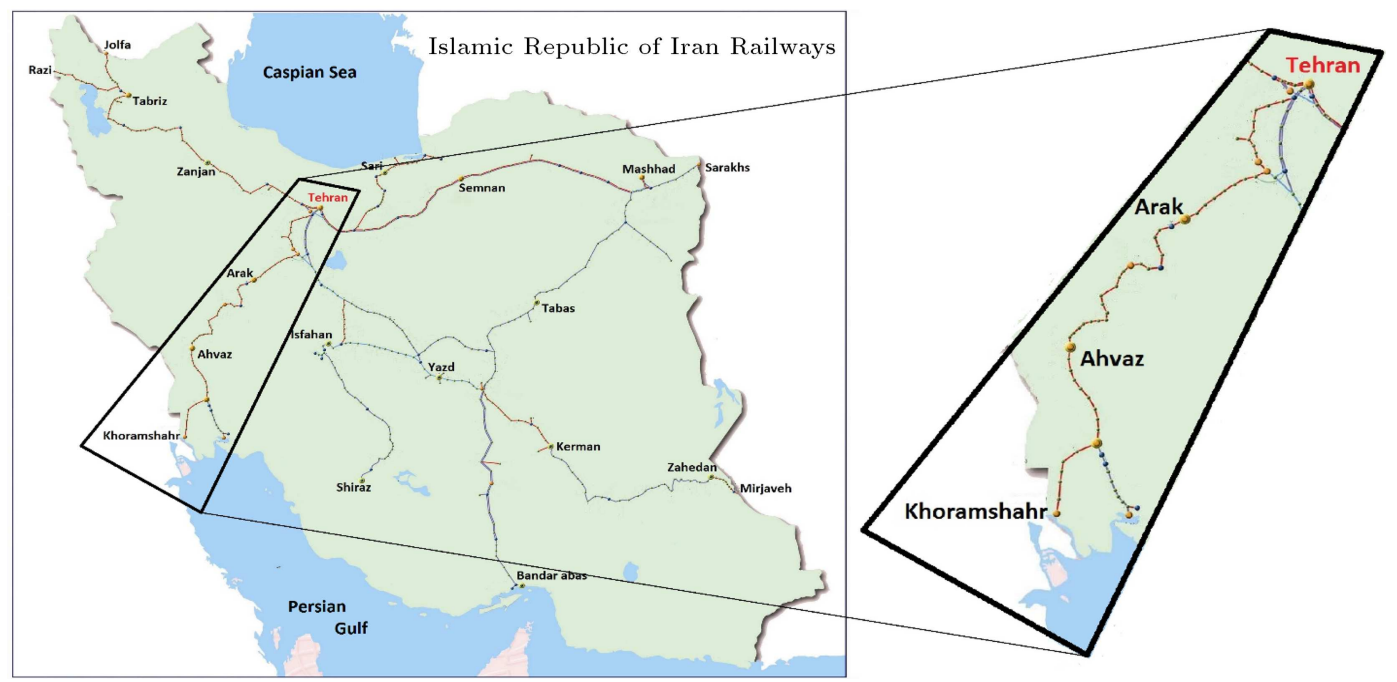

Figure 2. The map of (a) Iran's railway system, and (b) Iran's Southern Line railway.

\section{Materials and methods}

\subsection{Characteristics of the railway}

Table 1 shows the five major rail lines in Iran's railway system. One of the most significant and longest rail lines for passenger and freight transportation from Tehran to Khorramshahr is the "Southern Line" (Figure 2). This railway line passes through five different provinces of Iran, such as Tehran, Qom, Central, Lorestan, and Khuzestan, and connects Iran's capital, Tehran to three important international transit ports "Imam Khomeini", "Mahshahr", and "Khorramshahr". The characteristics of this line are presented in Table 2. According to Table 2, a large number of sharp curves is noticeable in this line. This path has been chosen for the high rate of wheels' flange wear which leads to a significant reduction in wheel longevity.

\subsection{Wagon, rail, and wheels}

A wagon from the "Plure Sabz" type train with bogies of type MD523 traveling on the Southern Line was selected to study the wear of wheel profiles in a real scale. Each wagon has a capacity of 40 passengers (10 compartments of 4 persons). The wagon wheels have the standard S1002 type profile whose geometry

Table 2. Characteristics of the Southern Line railway of Iran.

\begin{tabular}{lc}
\hline \multicolumn{1}{c}{ Variable } & Value \\
\hline Railway length $(\mathrm{km})$ & 905 \\
Min track curve $(\mathrm{m})$ & 218 \\
(Max-min) altitudes $(\mathrm{m})$ & 1171 \\
Track curves radius $(\mathrm{m})$ & $218-1500$ \\
Number of track curves & 373 \\
Number of track curves $<300 \mathrm{~m}$ & 43 \\
\hline
\end{tabular}

and parameters are shown in Figure 3(a). Figure 3(b) shows a schematic of the wagon and the wheel numbers. The limits of the wheel profile parameters are found in UIC510-2 standard [24]. For example, the wheel flange thickness limit for the detachment of the wagon in order to repair the worn wheel profile is $22 \mathrm{~mm}$.

\subsection{Measuring instrument}

The most widely used tools for measuring the wheels' parameters are compound caliper and laser view devices (Figure 4). The compound caliper is a manual instrument that is affected by human error in data recording, while the laser view is an automatic device which records the profiles using a laser beam (without sensitivity to ambient light) and automatically measures the wheels' parameters. In this work, the laser view is employed.

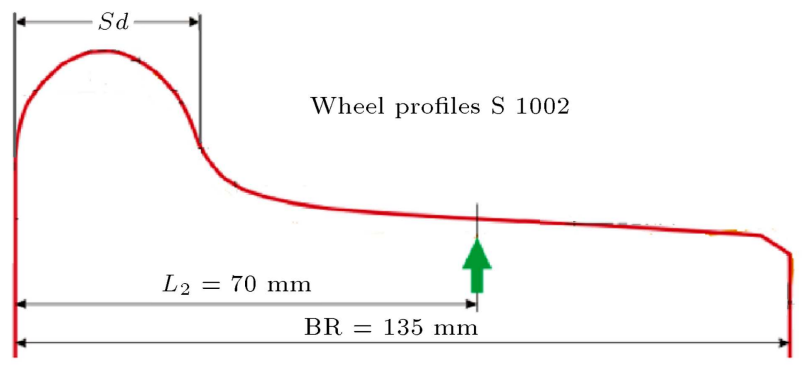

(a)

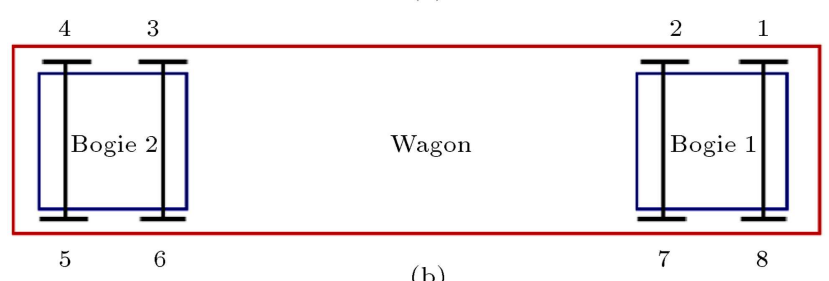

(b)

Figure 3. (a) The standard wheel profile of S1002. (b) The schematics of wagon, bogies, and wheels numbering. 


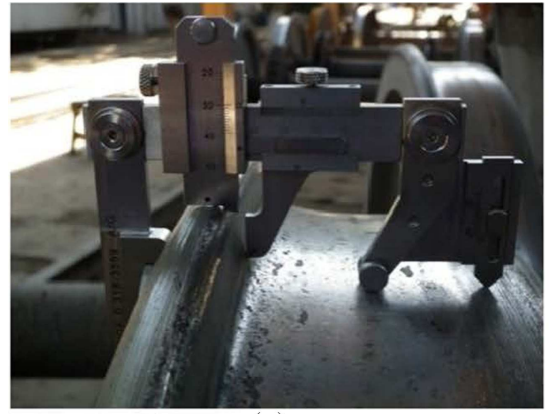

(a)

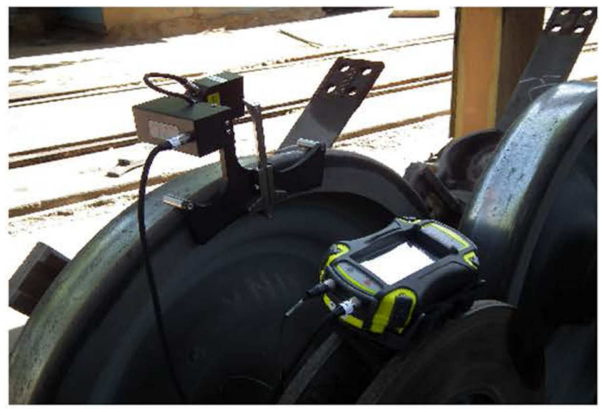

(b)

Figure 4. The instruments used to measure the wheel profile parameters: (a) Compound caliper, and (b) laser view.

\subsection{Measuring, recording, and analyzing the worn wheel profiles}

In this work, measurements are performed in real scale and actual operating conditions. Worn wheel profiles are recorded for each round trip of the train. The data acquisition is performed until the wheel flange thickness reaches the limit of $22 \mathrm{~mm}$ (as in the standard UIC510-2 [24]) for the detachment of the wagon in order to repair the worn wheel profile. The wear behavior of the wheels is obtained by focusing on the flange thickness parameter of worn wheels ( $S d$ parameter, defined in the standard UIC-510-2 [24]). The curve fitting techniques are utilized to express the mathematical relationship between the $S d$ parameter and the traveled distance of the wagon.

\subsection{The curve fitting techniques}

The least squares method is employed to fit curves to the results of experimental measurements. A parametric polynomial equation is defined which predicts the response data to the predictive data with one or more coefficients. Polynomial functions of order one (linear) as well as polynomial functions of higher orders are evaluated to achieve a desirable fitting accuracy.

$$
y=a_{n} x^{n}+a_{n-1} x^{n-1}+\cdots+a_{2} x^{2}+a_{1} x+a_{0} .
$$

In order to approximate the coefficients, the least squares method minimizes the summed square of residuals. The residual (Eq. (2)) for the $i$ th data point, $r_{i}$, is defined as the difference between the observed response value, $y_{i}$, and the fitted response value, $\hat{y}_{i}$, and is identified as the error associated with the data:

$$
\begin{aligned}
& r_{i}=y_{i}-\hat{y}_{i}, \\
& S=\sum_{i=1}^{n} r_{i}^{2}=\sum_{i=1}^{n}\left(y_{i}-\hat{y}_{i}\right)^{2} .
\end{aligned}
$$

The coefficients obtained from each fitting procedure can help to determine the best fit (Table 3 ).

\section{Results and discussion}

In this section, the experimental results of wheel flange wear due to the train traveling on the rail track consisting of many consecutive or distinct sharp curves are presented and discussed. In addition, the maintenance technique of the "first and second limits" is suggested and discussed. This technique is based on the $S d$ limit for the detachment of a wagon for repair of the first worn wheel when it reaches the first limit, while the other wheels are checked with the second limit for applying (or not) the repairing procedure to them.

\subsection{Wear behavior of wheels}

The wagon sweeps along the $905 \mathrm{~km}$ railway route of the Southern Line in Iran. The wheels' profile data are recorded for each round trip of train or every $1810 \mathrm{~km}$. The wheel flange thicknesses of profiles are measured and recorded by the laser view instrument until reaching the investigated limit of $22 \mathrm{~mm}$. Ac-

\begin{tabular}{|c|c|c|}
\hline Variable & Definition & Effects on the fit \\
\hline Adj R-square & Degrees of freedom adjusted R-square & Better fit for a value closer to 1 \\
\hline R-square & $\begin{array}{l}\text { Square of the correlation between the } \\
\text { response and the predicted response values }\end{array}$ & Greater variance for a value closer to 1 \\
\hline RMSE & Root Mean Squared Error & Better fit for a value closer to 0 \\
\hline SSE & Sum of squares due to error of the fit & Better prediction for a value closer to zero \\
\hline
\end{tabular}
cording to Figure 3, the wagon has four axles. The

Table 3. Comparable goodness variables in the fitting procedure. 


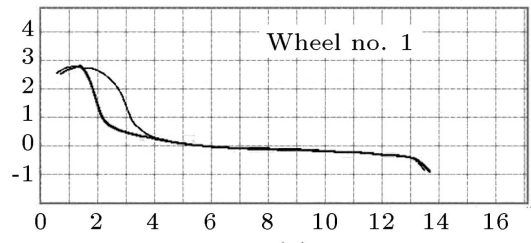

(a)

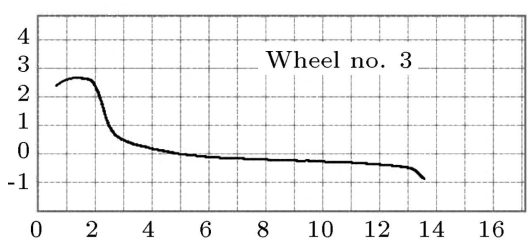

(c)

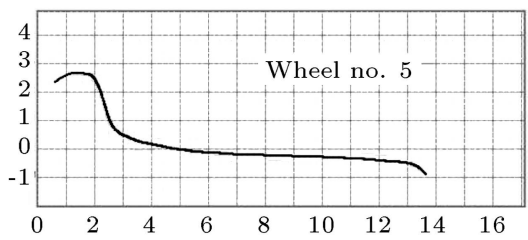

(e)

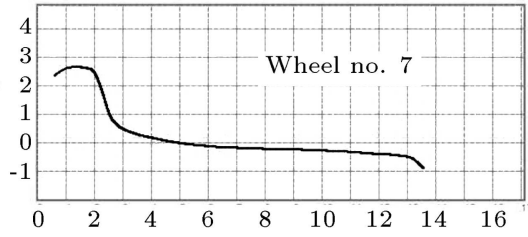

(g)

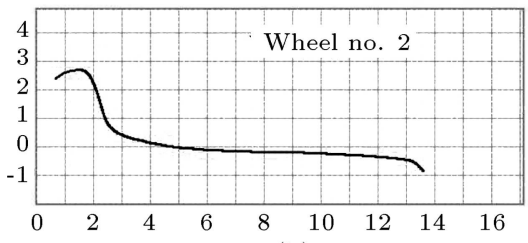

(b)

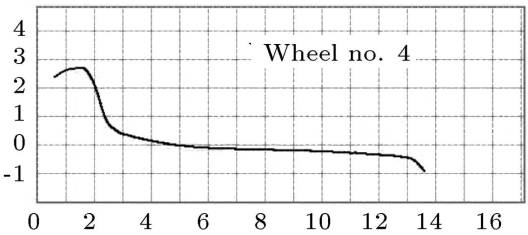

(d)

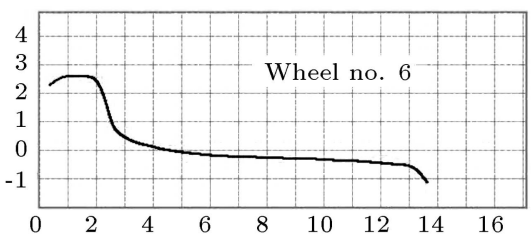

(f)

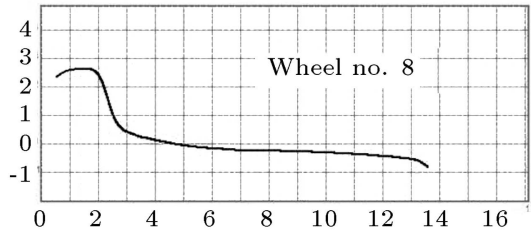

(h)

Figure 5. The worn profiles of all wheels of the wagon after detachment of the wagon in order to repair the wheels. The initial wheel profile is illustrated at the subplot of (a) wheel no. 1, (b) wheel no. 2, (c) wheel no. 3, (d) wheel no. 4, (e) wheel no. 5 ; f) wheel no. 6 , (g) wheel no. 7 , and (h) wheel no. 8.

first wheel in each axle that reaches the defined wheel flange thickness limit for the detachment of the wheel to repair is called the "critical wheel of that axle". In addition, each wheel that causes the detachment of the wagon in order to repair the wheel is called the "critical wheel of wagon".

After traveling about $40,000 \mathrm{~km}$ in the introduced rail route, the critical wheel of the first axle (wheel no. 1) severely sharpens and causes the detachment of the wagon. Figure 5 shows the worn profiles of all wheels of the wagon in its detachments for the repair of wheels. Moreover, the initial profile of the wheels is illustrated in the plot of the worn profile of the critical wheel of the first axle (wheel no. 1) for comparison. In Figure 5, it is observed that during the wagon detachment for wheel repair, only the wheel flanges are severely worn, while the wheel treads are not worn due to the small traveled distances traveled. The initial amount of wheel flange thickness $(S d)$ is $32 \mathrm{~mm}$. The amounts of wheel flange thickness when the critical wheels caused the wagon detachment to repair the wheels' profiles were recorded as 22.29 , $22.8,22.45$, and 22.9 for the first to fourth axles, respectively.

By recording the data of different wheels on the wagon, and then comparing their worn profiles, it was found that the wear behaviors of all wheels are similar. However, the amount of wheel flange wear depends on the position of the wheels on the wagon. In Figure 6, the wheel flange wear procedures for the critical wheels of four wagon axles are denoted. In addition, the curve fitting procedure, described in Section 2.5, was applied for various polynomial equations, and the best one was chosen to model the wear behavior of the four critical wheels of the wagon axles. In Figure 6, the fitted curves of $S d$ versus the traveled distance are shown. By comparing the evaluation parameters (goodness parameters), shown in Figure 6, it was found that a fifth order polynomial function is appropriate.

As it is observed in Figure 6, the critical wheel of the first axle is wheel no. 1 after a traveled distance of about $40,000 \mathrm{~km}$; the critical wheel of the second axle is wheel no. 7 after a traveled distance of about $54,000 \mathrm{~km}$; the critical wheel of the third axle is wheel no. 3 after a traveled distance of about $71,000 \mathrm{~km}$; the critical wheel of the fourth axle is wheel no. 4 after a traveled distance of about $75,000 \mathrm{~km}$, and the $S d$ of about 22 was reached and caused detachments of those wagons. These values are much less than the usual 


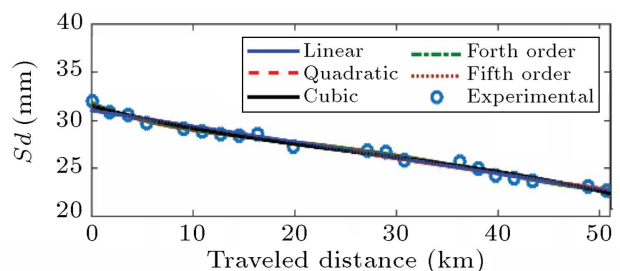

(a)

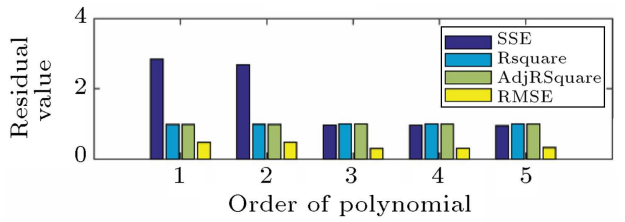

(c)
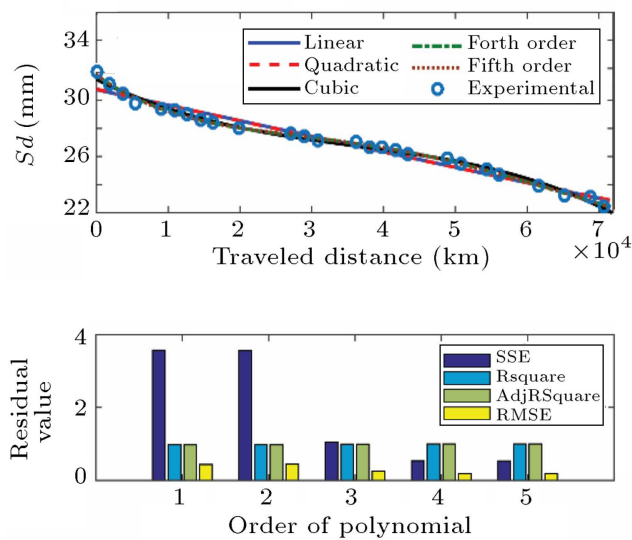

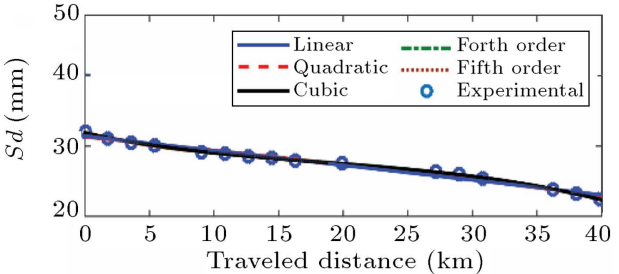

(b)
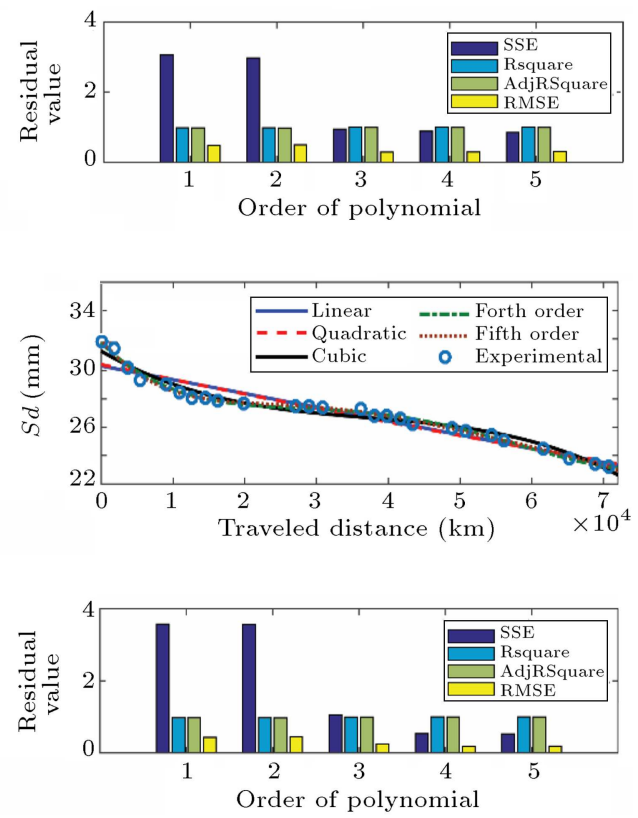

Figure 6. A comparison of the $S d$ trends versus the Travelled Distance (TD) (Figures 6(a), (b), (e), and (f)) and the corresponding Fitting Residuals (FRs) (Figures 6(c), (d), (g), and (h)) for four critical wheels of the wagon axles until the repair requirement with the standard limit of $S d=22 \mathrm{~mm}$ with the fitted curves and the evaluation parameters of fittings. Respectively, (a) and (c) are $S d$ vs. TD and FRs for wheel no. 1 (first axle); (b) and (d) are $S d$ vs. TD and FRs for wheel no. 7 (second axle); (e) and (g) are $S d$ vs. TD and FRs for wheel no. 3 (third axle); and (f) and (h) are $S d$ vs. TD and FRs for wheel no. 4 (forth axle).

amount of at least $500,000 \mathrm{~km}$ in normal railways for the detachment of the wagon in order to repair the wheels.

\subsection{The optimal maintenance technique for the wagon}

To reduce the maintenance costs of wagons and increase the longevity of the wheels particularly in railways with distinct and consecutive sharp curves, it is better to determine the appropriate conditions for wagon detachment and wheel repair.

\subsubsection{The "first and second limits" technique}

As mentioned in the previous section, the wheel repair (reprofiling) criterion in the standard UIC occurs when the $S d$ reaches a value of $22 \mathrm{~mm}$. In this technique, two limits for wagon detachment and critical wheels' repair are discussed. In standard UIC, the general case, $S d=22 \mathrm{~mm}$, is the only wheel factor that is checked. It should be noted that in conventional tracks, both tread and flange wear of wheels are important (in some straight tracks, only the tread is important). However, for particular railways, such as Southern Line of Iran, which include many distinct and consecutive sharp curves, the wheels' flange wear is much more important than the wheels' tread wear. Therefore, in these particular railways, only one limit is not optimal to determine the detachment of a wagon for wheel repair. This is because the determined limit considerably increases the number of wagon detachments, and hence the wagon maintenance costs. Due to the differences in wear rates and severe reductions of $S d$ at the critical wheels in different axles, it is possible to check and repair (if required) other wheels using another limit at the time when the wagon is detached to repair the critical wheel. This reduces the number of wagon detachments' traveled distance due to the severe flange wear in different wheels of the wagon. Before presenting this technique, the situations of wagon detachments due to the repair of different wheels should be investigated.

As can be seen in Figure 6, when all wheels are new, the first detachment of the wagon occurs at $40,000 \mathrm{~km}$ traveling distance due to the critical 
wheel of the first wagon axle. The second wagon detachment occurs about $14000 \mathrm{~km}$ after that (i.e., $54000 \mathrm{~km}$ from where the wagon first started) due to the critical wheel of the second wagon axle. The third wagon detachment occurs about $17000 \mathrm{~km}$ after that (i.e., $71000 \mathrm{~km}$ from where the wagon first started) due to the critical wheel of the second wagon axle. The fourth wagon detachment occurs about $4000 \mathrm{~km}$ after that (i.e., $75000 \mathrm{~km}$ from where the wagon first started) due to the critical wheel of the fourth wagon axle. This cycle is repeated with the exception of the second detachment of the first critical wheel in the first axle occurring at a distance of $5,000 \mathrm{~km}$ from the last detachment due to the fourth critical wheel (i.e., in approximately $80000 \mathrm{~km}$ from where the wagon first started). Therefore, five wagon detachments occur in an $80000 \mathrm{~km}$ traveled distance. Due to the high number of wagon detachments, the cost of wagon maintenance increases considerably due to wheel wear.

Our technique is based on two limits of critical flange thicknesses for the different wheels in order to determine the best time for detachment of the wagon or repair of other wheels during the wagon detachment. The first limit is used for the critical wheel of the wagon which leads to the wagon detachment, while the second limit is used to check the other wheels in other axles of the wagon during the wagon detachment. If the flange thickness $(S d)$ of each of the checked wheels in the other axles reaches the second level, the initial detachment time is exploited appropriately and repair is applied to those wheels preventing successive detachments in small-traveled distances of the wagon (i.e., traveled distances under $20,000 \mathrm{~km}$ ). By evaluating the first and second limits, optimum values of these variables could be obtained.

Implementation of this technique is based on the wagon detachment and wheel repair costs, taking into account the wear behaviors of all wheels of the wagon (Figure 6). Therefore, by employing fitted curves on the recorded wheels' profile wear data, the costs are calculated for several observed first and second limits. In this way, the optimal points at which the cost per traveled distance is minimum could be obtained.

\subsubsection{Available milling depth of wheel}

In order to repair the critical wheel of each axle and reuse it in the wagon, the wheel surface should be milled to form the standard shape of the wheel profile. Both of the opposing wheels in each axle are milled simultaneously by a special wheel milling machine. In cases where severe wheel flange wear occurs, the required area for milling to repair the wheel is substantial and a considerable amount of the available depth of the wheel is milled. The depth of the new wheel is $43 \mathrm{~mm}$. In addition, the minimum depth of the wheel according to the standard would be $10 \mathrm{~mm}$. Therefore, the available wheel depth for milling process is $33 \mathrm{~mm}$. In order to find the amount of the required milling to achieve the standard wheel profile with respect to the different flange thicknesses, the wheel is milled step by step. The profiles are measured and compared with the standard profile in each step.

By using the result of the laser view device and measuring the wheel profile, the required milling amount can be determined. The worn wheel can be attached to the wagon when its surface is milled until the standard profile is achieved. In cases where severe wear occurs in the wheel flange, the amount of the milling to achieve the standard profile is substantial. Therefore, a considerable amount of wheel depth is milled, and hence the number of re-profiling is reduced.

When the wagon is detached to repair the worn wheel, due to the severe wear of the wheel flange with respect to the wheel tread, approximately the entire initial depth is available for re-profiling. The available number of wheel re-profilings can be calculated based on the worn wheel flange thickness and its available depth before reaching the wheel depth limit of $10 \mathrm{~mm}$. For example, if $S d=22 \mathrm{~mm}$, the required amount of wheel re-profiling to achieve the standard profile is about $16.5 \mathrm{~mm}$ (obtained from the output of the milling machine). With the available depth of $33 \mathrm{~mm}$, the available number of wheel re-profiling is 2 . We can similarly obtain the available numbers of re-profiling with the range of $S d$. An increase in the number of re-profiling leads to an increase in the longevity of the wheel. Although maintenance costs are increased due to an increase in the number of re-profilings, the overall maintenance costs of wagon will still decrease due to the reduction of the wagon's detachment costs (which is about 7 times that of the re-profiling costs). In addition, the longevity of the wheels could be enhanced. This is done by obtaining the optimum points for the first and second limits.

To obtain optimal values of the first and second limits for the flange thicknesses of the worn wheel to repair (re-profiling) the wagon wheels, an objective function is defined based on the cost of the wheel (including the initial and re-profiling costs), the number of wheel re-profilings, the cost of the wagon detachment, and traveled distance of the wagon.

\subsubsection{The objective function}

The Objective Function (OF) that is the wagon maintenance costs with respect to the traveled distance is calculated based on the wheel costs $\left(W_{t}\right)$ including the initial wheel cost $\left(W_{i}\right)$ and the wheel re-profiling costs $\left(W_{r}\right)$, the wagon detachment costs $\left(D_{t}\right)$ in the numerator, and the final Traveled Distance of wagon 
Table 4. A comparison of the number of wheel re-profilings, number of wagon detachment, the traveled distance, and cost per traveled distance for three cases of the first and second limits of flange thickness selection.

\begin{tabular}{cccccccc}
\hline $\begin{array}{c}\text { Sd lower } \\
\text { bound } \\
(\mathbf{m m})\end{array}$ & $\begin{array}{c}\text { Sd upper } \\
\text { bound } \\
(\mathbf{m m})\end{array}$ & $\begin{array}{c}\text { No. } \\
\text { re-profiling }\end{array}$ & $\begin{array}{c}\text { No. } \\
\text { detachment }\end{array}$ & $\begin{array}{c}\text { Traveled } \\
\text { Distance } \\
\text { (TD) }\end{array}$ & $\begin{array}{c}\text { Relative } \\
\text { TD }\end{array}$ & $\begin{array}{c}\text { Cost per } \\
\text { traveled distance } \\
\text { (CTD) } \mathbf{( E u / k m )}\end{array}$ & $\begin{array}{c}\text { Relative } \\
\text { CTD }\end{array}$ \\
\hline 22 & 22 & 8 & 8 & 150852 & $0 \%$ & 0.1017 & $\mathbf{0 \%}$ \\
22 & 26 & 11 & 5 & 218740 & $+45 \%$ & 0.0624 & $\mathbf{- 3 8 . 6 4 \%}$ \\
26 & 26 & 12 & 9 & 163629 & $+8.47 \%$ & 0.0995 & $\mathbf{- 2 . 1 0 \%}$ \\
\hline
\end{tabular}

(TD) in the denominator of the fraction:

$$
\begin{aligned}
& \mathrm{OF}=\frac{W_{t}+D_{t}}{\mathrm{TD}}, \\
& W_{t}=W_{i}+W_{r}
\end{aligned}
$$

The cost of a new wheel $\left(W_{i}\right)$ is approximately 1,200 Euros, the wheel re-profiling costs $\left(W_{r}\right)$ are about 100 Euros, and the daily detachment costs of the wagon $\left(D_{t}\right)$ are about 700 Euros. To minimize the OF according to Eq. (4), it is necessary to maximize the traveled distance in the denominator and minimize the costs in the numerator. However, minimization of the objective function depends on the relationship of costs to traveled distance.

\subsubsection{Obtaining the optimal first and second limits}

To achieve the optimal values for the first and second limits, the objective function would be calculated in the allowable range of $S d$ (22 to $32 \mathrm{~mm}$ ). For this purpose, the objective function is calculated using the recorded field data for traveled distance and wheel re-profiling, as well as the simulation of different possible states, as presented in Table 4. The plot of the objective function (Cost per Traveled Distance (CTD)) (Eq. (4)) is represented in Figure 7 . The objective function in the first limit of $S d=22 \mathrm{~mm}$ and in the second limit of $S d=26 \mathrm{~mm}$ indicates the minimum value. The lowest amount of cost per traveled distance in this state is $0.00624 \mathrm{Eu} / \mathrm{km}$.

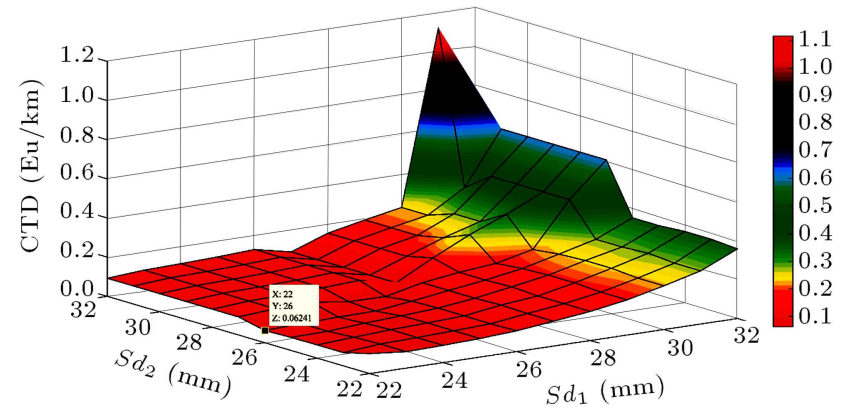

Figure 7. The objective function, i.e. CTD (cost per unit travelled distance) $(\mathrm{Eu} / \mathrm{km})$, for variable first and second limits of $S d$; minimum occurs at $S d_{1}=22 \mathrm{~mm}$, $S d_{2}=26 \mathrm{~mm}$, and CTD $=0.0624 \mathrm{Eu} / \mathrm{km}$.
In Table 4, the comparisons between some particular cases, i.e. wheel flange thicknesses of 22 and $26 \mathrm{~mm}$ for the first and second limits, are presented. These comparisons are based on the number of re-profiling, the number of wagon detachments, the traveled distance, the cost per traveled distance, and the relative percentages of the cost per traveled distance and distance traveled relative to the calculated amounts for the standard flange thickness $\left(S d_{1}=S d_{2}=22 \mathrm{~mm}\right)$. According to Table 4, it was found that if the first and second flange thicknesses are the same and equal to the defined limits of standard to detachment of the wagon for repairing the wheels, i.e. $S d_{1}=S d_{2}=22 \mathrm{~mm}$, the traveled distance of the wagon with eight new wheels is equal to $150,825 \mathrm{~km}$, and the cost per traveled distance is equal to $0.1017 \mathrm{Eu} / \mathrm{km}$. However, if the first and second limits are the same and equal to $26 \mathrm{~mm}$, the traveled distance increases as much as $8.47 \%$ and the cost per traveled distance decreases by $2.10 \%$. In addition, if the first and second limits are not the same and the first limit is $22 \mathrm{~mm}$ and the second limit is $26 \mathrm{~mm}$, the traveled distance of the wagon increases as much as $45 \%$, while the traveled distance of the standard flange thickness and the cost per traveled distance decrease as much as $38.64 \%$.

\section{Conclusion}

Wheel and rail wear, which reduces the efficiency and increases cost, is an inevitable problem in railway transportation systems. In common railways, wear occurs in all regions of the wheel surface. However, the rail and wheel contact in sharp curves leads to severe flange wear. In this paper, using the data field recording technique, the wear behavior of all wheels of a wagon was studied in the "Southern Line" of Iran's railway system which includes many consecutive and distinct sharp curves. These tracks were created due to the geographical conditions that can be found in many countries. Moreover, the strategy called the "first and second" limits was suggested to improve wheel longevity and minimize wagon maintenance costs.

Some of the important findings are:

1. Rail and wheel contact in sharp curves leads to severe flange wear, and hence in order to repair 
the worn, wagon detachment of wheel occurs at least $90 \%$ sooner than wagon detachment due to the tread wear in common railways;

2. The curve fitting technique is used to model the relationship between $S d$ and traveled distance, and the fifth order polynomial functions are obtained as appropriate functions;

3. Despite the similarity in the wear behavior of wheels in different axles, due to the different locations of wheels on the wagon, each axle has a critical wheel traveled distance that reaches the defined limit for the detachment of wagon and wheels repair at a specific traveled distance;

4. Wagon detachments for repair of the first to fourth critical wheels occur at traveled distances of about $40,000,54,000,71,000$, and 75,000 km, respectively. These values are much less than the usual value in conventional rail routes, i.e. $500,000 \mathrm{~km}$;

5. The initial flange thickness of the wheels is $32 \mathrm{~mm}$, and the final profiles, when the wheels are repaired, are $22.29,22.8,22.45$, and 22.9 for the first to fourth critical wheels, respectively;

6. In the "first and second limits" technique, two limits for wagon detachment and critical wheel repair in different axles are discussed. The numbers of available wheel reprofilings are obtained based on the flange thicknesses of the worn wheels and the available depth of wheels for milling process $(33 \mathrm{~mm})$;

7. The traveled distance with the conventional limit of $S d_{1}=S d_{2}=22 \mathrm{~mm}$ in standard is $150,825 \mathrm{~km}$, and the cost per traveled distance is $0.1017 \mathrm{Eu} / \mathrm{km}$. Obtaining the optimal limits for $S d_{1}=22 \mathrm{~mm}$ and $S d_{2}=26 \mathrm{~mm}$, the traveled distance of the wagon increases by as much as $45 \%$, and the cost per traveled distance of the wagon decreases by as much as $38.64 \%$ in comparison to the general limit $S d_{1}=S d_{2}=22 \mathrm{~mm}$.

\section{References}

1. Lewis, R. and Olofsson, U., Wheel-Rail Interface Handbook, Elsevier (2009).

2. Ashtiyani, I.H. and Ansari, M. "Determination of the wear criterion", ASME/IEEE 2006 Joint Rail Conference, American Society of Mechanical Engineers, pp. 91-95 (2006).

3. Telliskivi, T. and Olofsson, U. "Wheel-rail wear simulation", Wear., 257(11), pp. 1145-1153 (2004).

4. Enblom, R., Prediction of Wheel and Rail Wear: A Literature Survey (2003).

5. Company, R.R., Report for Maintenance of Wheels, Raja Railway Company, Iran (2014).
6. Vatn, J. "Maintenance in the rail industry", in Complex System Maintenance Handbook, pp. 509-531 Springer (2008).

7. Reddy, V., Chattopadhyay, G., Larsson-Kraik, P.-O. and Hargreaves, D.J. "Modelling and analysis of rail maintenance cost", International Journal of Production Economics, 105(2), pp. 475-482 (2007).

8. Sedighi, H.M. and Shirazi, K.H. "Bifurcation analysis in hunting dynamical behavior in a railway bogie: Using novel exact equivalent functions for discontinuous nonlinearities", Scientia Iranica, 19(6), pp. 1493-1501 (2012).

9. Xiao, X., Jin, X., Deng, Y. and Zhou, Z. "Effect of curved track support failure on vehicle derailment", Vehicle System Dynamics, 46(11), pp. 10291059 (2008).

10. Ansari, M. and Ashtiyani, I.H. "Simulation and fullscale measurement of the wear in curved tracks", Rail Conference, 2006. Proceedings of the 2006 IEEE/ASME Joint: IEEE, pp. 97-101 (2006).

11. Hertz, H. "On contact between elastic bodies", Reine Angew Math., 92, pp. 156-171 (1881).

12. Kalker, J. "Simplified theory of rolling contact", Delft Progress Rep., 1(1), pp. 1-10 (1973).

13. Enblom, R. "On simulation of uniform wear and profile evolution in the wheel-rail contact", Doctoral Dissertation, KTH (2006).

14. Li, Z., Wheel-Rail Rolling Contact and Its Application to Wear Simulation, TU Delft, Delft University of Technology (2002).

15. Bin Sudin, M. "Analytical study on wear interaction between rail-wheel", Applied Mechanics and Materials: Trans Tech. Publ., pp. 2406-2410 (2012).

16. Li, X. et al. "A new integrated model to predict wheel profile evolution due to wear", Wear, 271(1), pp. 227237 (2011).

17. Sharma, S.K., Sharma, R.C., Kumar, A. and Palli, S. "Challenges in rail vehicle-track modeling and simulation", International Journal of Vehicle Structures and Systems, 7(1), pp. 1-9 (2015).

18. Zobory, I. "Prediction of wheel/rail profile wear", Vehicle System Dynamics, 28(2-3), pp. 221-259 (1997).

19. Jendel, T. and Berg, M. "Prediction of wheel profile wear: Methodology and verification", Vehicle System Dynamics, 37, pp. 502-513 (2002).

20. Blokhin, E., Psinko, O., Danovich, V. and Korotenko, M. "Effect of the state of car running gears and railway track on wheel and rail wear", 4th International Conference on Railway Bogies and Running Gears, Budapest, pp. 21-23 (1998).

21. Ushkalov, V., Mokriy, T. and Shevtsov, I. "On effect of bogie construction on dynamic performance of railway vehicles and their wheel wear", 4th International Conference on Railway Bogies and Running Gears, Budapest, pp. 21-23 (1998). 
22. Jin, X. "Experimental and numerical modal analyses of high-speed train wheelsets", Proceedings of the Institution of Mechanical Engineers, Part F: Journal of Rail and Rapid Transit, 230(3), pp. 643-661 (2014).

23. Baharom, M. "Experimental prediction of wear rate on rail and wheel materials at dry sliding contact", MATEC Web of Conferences: EDP Sciences, p. 03013 (2014).

24. International Union of Railways "Trailing stock: wheels and wheelsets. Conditions concern", UIC Code 510-2 (2004).

\section{Biographies}

Seyyed Miad Salehi is a PhD student in the School of Mechanical Engineering at Sharif University of Technology in Tehran. In his PhD thesis, he is currently working on the train's wheels wear in railways consisting several sharp curves. He has received several national and international awards and prizes in his various activities such as the nation's leading student in 2012 and Kharazmi Young Award in 2007 and 2012.

Gholam Hossein Farrahi received his $\mathrm{PhD}$ degree in Mechanical Engineering in 1985 from ENSAM, Paris, France. He is currently the Chairman and Professor of the School of Mechanical Engineering, Sharif University of Technology, Tehran, Iran. He is also the Head of Materials Life Assessment and Improvement Laboratory. His research interests include structural integrity assessment, failure analysis, fatigue, wear and life improvement methods.

Saeed Sohrabpour received his $\mathrm{PhD}$ degree in Mechanical Engineering in 1971 from University of California, Berkeley, USA. His research interests include large deformations, mechanics of metal forming, and optimal design. 